\title{
Türkiye'de Afet Zararlarını Azaltma Çalışmaları: Mevzuat Açısından Genel Bir Değerlendirme
}

\author{
Engin KEPENEK*, Ziya GENÇEL \\ Süleyman Demirel Üniversitesi, Mimarlık Fakültesi, Şehir ve Bölge Planlama Bölümü, 32260, Isparta, \\ Türkiye. \\ *e-mail: enginkepenek@sdu.edu.tr \\ Öz \\ Doğa olaylarının afet şeklini alması insanların oluşturduğu sistemlerin bir sonucudur. Bu sistemlerin \\ devamılı̆̆ını ya da sürekliliğini sağlayan ise, tabi oldukları yasal dayanaklar ve yönetmeliklerdir. ilgili mevzuat \\ çerçevesinde tanımlanan kurallar da, zaman içerisinde teknoloji ve ihtiyaçlar doğrultusunda değişirler. \\ Türkiye'de afet zararlarını azaltma çalışmalarına yönelik ilgili yasa ve yönetmeliklerde yapılan değişimler hep \\ yaşanan afetler, talihsiz olaylar ve tecrübeler sonrası gerçekleşmiştir. Cumhuriyet tarihimizde 1939 Erzincan \\ Depremi ile başlayan depremlerin neden olduğu zararları azaltılma çalışmaları bugün dahi istenilen düzeye \\ erişememiştir. Hatta 1999 Marmara depremine kadar yapılmış çalışmaların çoğunun afet sonrası oluşan \\ zararların giderilmesi yönünde olduğu gözlenmektedir. \\ Bu bağlamda, yaşanan 1999 Marmara depremi sonrası, Türkiye'de afet zararlarını azaltma çalışmalarına \\ yönelik denetim ve mevzuat yetersizlikleri sorgulanır hale gelmiştir. Oluşturulan yeni gündem neticesinde, \\ TÜBiTAK ve çeşitli üniversitelerin de katıldığı "proje odakı" uygulamaya dönük bir dönem başlamıştır. Bu \\ çalışmada, Osmanlı döneminden günümüze kadar geçen süreçte, ülkemizde yürürlüğe girmiş yasal \\ düzenlemeler kapsamında yapılan uygulamalarla birlikte ne tür sorunlar ile karşılaşıldığı ve çözüm önerilerine \\ yönelik genel bir değerlendirme yapılmıştır. Ayrıca bugün halen yürürlükte olan "6306 sayılı Afet Riski Altındaki \\ Alanların Dönüştürülmesi Hakkında Kanunun" işleyişi eleștirel bir bakış açısı ile incelenmiştir.
}

Anahtar Kelimeler: Afet Zararlarının Azaltılması, 6306 Sayılı Kanun, Afet Yönetmeliği

\section{Disaster Mitigation Studies in Turkey: An Overall Assessment in Terms of Laws and Regulations}

\begin{abstract}
Natural events take the form of disaster is a result of man-made systems. Legal basis and regulations allows the continuity of these systems. The rules that are defined by legislation, over time, they change according to needs and technology... The changes made in the laws and regulations related to disaster mitigation in Turkey occurred after the unfortunate events and experienced disasters. Starting from the 1939 Erzincan earthquake of harm reduction efforts is not at the desired level even today.. In fact, it is observed that most of the work until 1999 Marmara earthquake is the elimination of the losses occurred after disasters.

In this context, after the 1999 Marmara earthquake, lack of supervision and legislation for disaster mitigation work in Turkey has become questionable. Created as a result of the new agenda, TUBITAK and the participation of various universities "project-oriented" applications began facing a period.. In this study, a general assessment of solutions was made about the applications under the legislation and the problems that our country is faced in the period from the Ottoman to the present day. In addition, which is still in force today "the Law on Transformation of Areas under the Disaster Risk No. 6306" was examined in a critical perspective.
\end{abstract}

Keywords: Disaster Mitigation, Law No. 6306, Disaster Regulations

1. Giriş

Kent Bilim Terimleri Sözlüğünde "doğal kıran" olarak nitelendirilen doğal afet (yıkım) "fiziksel alt 
yapının, üstyapıda önemli değişmelere yol açarak, yerel toplulukların genel yaşamını etkileyen, aksatan, bozan yer sarsıntısı, yangın, su baskını, yer kayması, çı̆̆ ve kaya düşmesi gibi olaylar ve sonuçları" olarak tanımlanmaktadır (Keleş, 1998).

Afetlerin salt bir doğa olayı olduğunu söylemek kavramsal olarak yapılan en büyük hatalardandır. Afetler, doğal tehlikelerin ve insani kırılganlıkların çakışmasının bir sonucudur. Yani bir tehlike kendi başına afet durumunu oluşturmaz. Afet, insani sistemlerin ve bununla ilgili kırılganlıkların yarattığı bir sonuçtur. Bu iki etki, zaman ve mekânda aynı koordinatlarda buluştuğunda doğal afetler meydana gelmektedir (Alcantara, 2002).

Afetler dünyanın her yerinde meydana gelmelerine karşın, özellikle gelişmemiş ve gelişmekte olan ülkelerde etkileri çok daha büyük olmaktadır. Kentler içerisinde ise en yıkıcı etkiler en yoksul ve hatalı yapılaşmış mahalleler bir diğer deyişle en kuralsız yapılaşmış alanlarda meydana gelmektedir. Kısaca afetin oluşumu doğanın bir işi değil insanın kurduğu bir sistemin sonucudur. Bu kırılganlığın azaltılmasında sistem bir bütün olarak ele alınmalı, yasal yönetsel, sosyal ve ekonomik gelişmeler bir arada sağlanmalıdır.

Ülkemiz içerisinde bulunduğu jeolojik ve topoğrafik özellikleri nedeniyle, sık sık deprem gerçeği ile yüzleşmekte ve her seferinde önemli ölçüde can ve mal kayıplarına uğramaktadır. 1900'lerin başından bu yana 158 hasar yapıcı deprem meydana gelmiş bu depremlerde 97200 kişi yaşamını yitirmiş 175000 kişi yaralanmış, 583371 bina yıkılmış veya hasar görmüştür (Taymaz, 2001). Sadece yakın tarihimize baktığımızda dahi çok büyük yıkıcı depremler yaşanmıştır. Bunlardan en çok bilinen 1939 yılında 32700 kişinin yaşamını yitirdiği Erzincan ve 1999 yılında 17000 kişinin yaşamını yitirdiği Marmara depremleridir. Bu depremler haricinde ülkemiz yakın geçmişte binler ile ifade edilen birçok yıkıcı deprem yaşamıştır.

Yukarıda belirtilen rakamlardan da anlaşılacağı gibi Türkiye, tehlikeli coğrafi yapısına karşın, afetler karşısında bu kadar hazırlıksız olması nedeni ile büyük bedeller ödemiştir. Bu afetlerin oluşmasındaki en büyük etkenlerden biri yetersiz yönetmelikler, eksiz uygulama kararları ve bunların bir sonucu olarak oluşan plansız yapılaşmadır. Yapılmış olan bu çalışmadan da anlaşılacağı gibi ülkemiz için belki de en talihsiz durum proje odaklı olsun yönetsel odaklı olsun zarar azaltma çalışmalarının ne yazık ki yaşanan talihsiz olaylar ve tecrübeler sonrası başladığı veya hız kazandığıdır.

\section{Materyal ve Yöntem}

Bu bölümde, afet zararlarını azaltmak için Türkiye'de yürürlüğe girmiş yasal çalışmalar incelenerek ülkemizde deprem risklerinin azaltılması sürecine sağladıkları katkılar ve bu yasaların ortaya çıkış süreçleri kronolojik olarak yaşanan hadiseler ile birlikte irdelenmiş bu kapsamda genel bir değerlendirme yapılmıştır.

Türkiye'de deprem zararlarının azaltılmasına yönelik yapılmış yasal çalışmaların ülkemizin yaşadığı hadiseler ile ilişkileri kurulduğunda planlama disiplini açısından öncelikle 2 temel dönemde incelemek mümkündür. Bu dönemlerden ilki 1999 Marmara depremi öncesi daha çok deprem sonrası oluşan zararları azaltmaya yönelik düzenlemelerin yer aldığı dönem, ikincisi ise 1999 depremi sonrası uluslararası işbirliği ve üniversitelerin katılımı ile sağlanan proje odaklı dönemdir. Çalışmada buna ek olarak bugün gelinen nokta ve getirdiği yenilikler ile 2012 yılında yürürlüğe 6306 sayılı kentsel dönüşüm yasası ayrı ele alınmıştır. Birçok yeniliğe sahip olan 6306 sayılı yasanın yeni bir dönem açıp açmadığı ancak yapılan çalışmaların sonuçları incelendiğinde belirlenebilecektir.

\subsection{9 Öncesi Dönem}

Osmanlı Devleti'nde Tanzimat Dönemi'ne kadar afet sonrası padişah fermanları ile yaraların sarılmaya çalışıldığı ancak afet öncesi zarar azaltmaya yönelik bir çalışmanın olmadığı görülmektedir. Tanzimatlar ile başlayan reform hareketleri ile 1848 yılında "Nafia Nezareti" (Bayındırlık işlerinden sorumlu kurum) kurulmuş, imar faaliyetlerine ilişkin Ebniye (Yapı) Nizamnamesi çıkartılmıştır. Bu Nizamname (Yönetmelik) ile yapılaşma ile ilgili esaslar belirlenmiştir. Bu esasların uygulanması için ise önce İstanbul da daha sonra tüm İmparatorluk da Belediye teşkilatları kurulmaya başlanmıştır (Tekdemir, 2011). 
Cumhuriyetin kuruluşu ve sonrasında yaşanan mübadele ile gelenlerin iskân sorunlarını çözmek üzere Mübadele ve İmar İskân Bakanlığı kurulmuştur. Ancak bu bakanlığın ömrü uzun sürmemiş bir yıl sonra kapanmıştır (Göktürk ve Yılmaz, 2005). 1930 yılında yürürlüğe giren Belediye Kanunu ve 1933 tarihinde yürürlüğe giren "Belediye Yapı ve Yolları Kanunu" ile Belediyelerin görevleri yeniden tanımlanmış o tarihe kadar halen yürürlükte olan "Ebniye Nizamnamesi" değiştirilmiştir. Bu kanunlar ile birlikte Belediyelere imar planlarını hazırlanma zorunluluğu gelmiştir (Çevre ve Şehircilik Bakanlığı, 2015).

1939 Aralık ayında yaşanan Richter ölçeğine göre 7,9 büyüklüğünde, 32.962 kişi hayatını kaybettiği, yaklaşık 100.000 kişinin yaralandığı, 116.720 binanın yıkıldığı Türkiye'nin en ciddi deprem felaketlerinden birisi olarak tarihe geçen Erzincan depremi sonrası "Erzincan'da ve Erzincan Depremi'nden Müessir Olan Mıntıkalarda Zarar Görenlere Yapılacak Yardımlar Hakkında Kanun" çıkarılmıştır (Çevre ve Şehircilik Bakanlı̆̆ı, 2015). Bu kanun ile vergi mükelleflerinin vergi borçlarının silinmesi, evleri yıkılan veya hasar görenlere ücretsiz arsa ve yapı malzemesi yardımı yapılması, memur ve diğer çalışanlara avans verilmesi, mahkûmların cezalarının affedilmesi, yapılacak taşımalarda ücret indirimi ile yurt dışından gönderilen yardım malzemelerinin gümrük vergisi ve diğer harçların kaldırıması kanun kapsamına altına alınmıştır. Ancak yapılan çalışmaların ve çıkartılan yasaların hiçbiri afet öncesi zararların azaltılması çalışmalarına örnek olamamıştır. Bunun anlaşılması sonrası 1944 yılında "Yer Sarsıntılarından Evvel ve Sonra Alınacak Tedbirler Hakkında Kanun" ile afetten önce ve sonra neler yapılacağı yasa ile belirlenmiş bu yasada belirlenenler ışığında Türkiye Cumhuriyetinin ilk yapı yönetmeliği ve deprem bölgeleri haritası hazırlanmıştır (Anonim, 2004).

1945 yılında yürürlüğe giren "Yer Sarsıntılarından Evvel ve Sonra Alınacak Tedbirler Hakkında Kanun" ve sonrasında çıkan ilk yapı yönetmeliği sayesinde ülkemiz de afet zararlarını azaltma çalışmalarının başladığı söylenebilir çünkü 1933 tarihinde yürürlüğe giren "Belediye Yapı ve Yolları Kanun'da ve Ebniye Nizamnamesinde" hiç değinilmeyen "deprem" kavramı kanunda yerini almış ve deprem bölgelerinde yapılacak binalara ilişkin kurallar, jeolojik etüt çalışmaları gibi birçok gerekli düzenleme yürürlüğe girmiştir. Ayrıca afet öncesinde acil yardım ve kurtarma planlarının hazırlanması, yöneticilerin ve halkın görevlerine ilişkin sorumlulukları gibi birçok konu bu kanunda yer almıştır (Anonim, 2004). Ne yazık ki bu yasa ile ilgili çalışmalarda ülkemizdeki birçok afet çalışması gibi yaşanmış afetler sonrası başlamıştır.

Sonraki dönemlerde deprem yönetmelikleri gelişmeye devam etmiştir. Örneğin 1945 yılında betonarme binalardan hiç söz edilmezken 1949 yılında yürürlüğe giren yönetmelikte 1 . ve 2 . derece deprem bölgelerinde bulunan betonarme yapılara etkiyen deprem kuvvetlerinin hesaplanması için basit bir hesaplama yöntemi bulunmaktadır (Alyamaç ve Erdoğan, 2005). 1953 yılına gelindiğinde 1949 yılında çıkartılan yönetmelik yerini "Yersarsıntısı Bölgelerinde Yapılacak Yapılar Hakkında Yönetmeliğe" bırakmış gelişmelerin devamı ile deprem kuvvetlerinin hesabı daha ayrıntılı hale getirilmiş ve açıklayıcı tablolara yönetmelikte yer verilmiştir. Aynı yıl Yapı ve İmar İşleri Reisliği bünyesinde bir deprem bürosu kurulmuş, bu büro, 1955 yılında yine aynı Reisliğe bağlı olarak DE-SEYA (Deprem, Seylab, Yangın) Şubesi haline getirilmiştir. 1957 yılına gelindiğinde ülkemizde planlama disiplini için en önemli kırılma noktalarından biri sayılacak ve 1984 yılına kadar yürürlükte kalacak olan İmar Kanunu çıkmıştır. Yasa ile ülkemizde ilk kez planlama disiplini yönetmelikler ile afet zararlarının azaltılmasına dâhil olmuş, belediye ve mücavir alanlar içerisinde planlama, belirli kurallara bağlanmış, yeni iskân alanlarında doğal afet tehlikesinin dikkate alınması öngörülmüştür (Yavaş, 2001). Kanunu takiben kanunun uygulanması amacı ile aynı yıl İmar ve İskân Bakanlığı kurulmuştur.

1957 yılında yürürlüğe giren ve ülkemizin ilk imar kanunu niteliğinde olan yasa ile planlamanın afet zararlarını azaltmada bir araç olarak kullanılacağının tanımlanması ile bu konuda ülkemiz için yeni bir dönemin başladığı söylenebilir. 1959 yılında İmar ve İskân Bakanlığı kurulması ve aynı yıl "Umumi Hayata Müessir Afetler Dolayısıyla Alınacak Tedbirlerle Yapılacak Yardımlara Dair Kanun" ya da diğer bir ifade ile "Afet Kanununun" yürürlüğe girmesi ile hem o zamana kadar yapılmış olan kanunlar tek bir kanunda toplanmış hem de kanunu uygulayacak yetkili kurum belirlenmiştir (Çevre ve Şehircilik Bakanlığı, 2015). 
1962 yılında "Umumi Hayata Müessir Afetler Dolayısıyla Alınacak Tedbirlerle Yapılacak Yardımlara Dair Kanun" kapsamında teknik eksiklerin giderilmesi için bir ilk olarak "Afet Bölgelerinde Yapılacak Yapılar Hakkında Yönetmelik" hazırlanmış ve yürürlüğe girmiştir (Anonim, 1962). Yönetmelikte yapının taşıyıcı sistemlerinin yapının eksenlerine göre simetrik olmasından bahsedilmiş ancak ayrıntılı kurallar ve formüller verilmemiş tavsiye niteliğinde sınırlı kalınmıştır (Çevre ve Şehircilik Bakanlığı, 2012).

Temmuz 1965 'de, İmar ve İskân Bakanlığının kuruluş ve görevlerinde yapılan değişiklik ile Afet İşleri Reisliğinin görev ve yetkilerinde de değişiklikler yapılmıştır. Buna göre kurum arama-kurtarma, güvenlik ve sağlık hizmetleri dışında tam yetkili hale gelmiştir. Ayrıca o sene tüm diğer devlet kurumlarının olduğu gibi reislik ismi yerini genel müdürlüğe bırakmıştır (Çevre ve Şehircilik Bakanlığı, 2015).

1968 ve 1975 yıllarında ülkemizde betonarme yapı stokunun artması ile 1962 yılında çıkan "Afet Bölgelerinde Yapılacak Yapılar Hakkında Yönetmelikte" bulunan teknik eksiklikler giderilmeye çalışılmış inşaat elemanlarından, inşaat boyut ve donatı kurallarından bahsedilmiş, deprem hesabı ayrıntılı hale getirilmeye çalışılmıştır (Anonim, 1968 ve 1975). Yönetmelikte bu tarihten itibaren isim değişikliği veya genel bir değişik olmamış düzeltmeler ve detaylandırılmalar ile gelişimine devam etmiştir.

1983 yılında Bayındırlık Bakanlığı ile İmar ve İskân Bakanlığı birleştirilmiş Bayındırlık ve İskân Bakanlığı kurulmuştur. 1985 tarihinde ise günümüzde de yürürlükte olan 3194 sayılı İmar Kanunu çıkartılmıştır. Kanun'un getirdiği en önemli yenilik, imar planlarının yapımı ve yürütülmesi konularının detaylı açıklamalar getirmiş olması ve mahalli idarelere verdiği yetkilerdir. Ancak yasada olması gereken afet odaklı planlama ilkeleri yerini bulamamıştır.

1992 tarihinde yaşanan Richter ölçeğine göre 6,8 büyüklüğünde Erzincan depremi ile 653 kişi yaşamını yitirmiş 8057 binan hasar görmüştür. Bu afet sonrası “Erzincan, Gümüşhane ve Tunceli illerinde Vuku Bulan Deprem Afeti ile Şırnak ve Çukurca'da Meydana Gelen Hasar ve Tahribata illişkin Hizmetlerin Yürütülmesi Hakkında Kanun" çıkartılmıştır. Bu kanun ile kalıcı bir çözüm sunulmamış sadece afet zararları telafi edilmeye çalışımıştır (Alyamaç ve Erdoğan, 2005).

Bugün yürürlükte olan 2007 deprem yönetmeliğinin temelleri 1998 yılında çıkartılan yönetmelik ile atılmıştır. Bu yönetmelikte birçok yenilik getirilmiş her bir yapı türü alt başıkta toplanmış sadece betonarme yapılar değil, çelik, ahşap, yığma yapılar içinde depreme dayanıklı tasarım kuralları belirlenmiştir. Her bir yapı elemanı için kurallar şekillerle detaylı bir şekilde açıklanmıştır. Yapılarda düzensizlik kavramı ilk kez bu yönetmelikte dile getirilmiş, yatay ve düşey olarak düzensizlikler tanımlanmış, binalar da bu düzensizliklerin bulunmaması istenmiştir.

\subsection{Sonrası Dönem}

1999 Marmara Depremi sonrası, Türkiye'nin doğal afetlere karşı yetersiz ve hazırlıksız olduğu bir kez daha anlaşılmıştır. Bu tarihten sonra sadece yasal açıdan değil aynı zamanda proje odaklı bir dönem başlamıştır. Bunun en büyük nedeni artık tek sorunun yeni yapılacak alanlar değil, mevcut yapılaşmış alanlardaki dayanıklı olmayan yapı stokunun oluşmuş olmasıdır. Artık yapılması gereken bu stokun dönüştürülmesi, yeni yapılacak yapılarında standartlarının da yükseltilmesi gerekliliğidir. Bu süreçte yurtdışı projeleri incelenmiş, uluslararası işbirliği çalışmaları başlamıştır.

17 Ağustos 1999 Depremi'nin üzerinden hemen 1 ay sonra afetin yaralarını sarmak ve etkin bir organizasyon yapısı oluşturmak üzere "Doğal Afetlere Karşı Alınacak Önlemler ve Doğal Afetler Nedeniyle Doğan Zararların Giderilmesi Iç̧in Yapılacak Düzenlemeler Hakkında Yetki Kanunu" ile Bakanlar Kurulu'na on ay süre ile ilgili kuruluşlar arasında koordinasyon ve eşgüdümün sağlanması, güvenli yeni yerleşimlerin kurulması, yeni bir sigorta sisteminin kurulması, depremin etkilediği bölgede yeni il ve ilçeler ile büyükşehir belediyeleri kurulması gibi konularda kanun hükmünde kararname çıkartma yetkisi verilmiştir. Afetin büyüklüğü göz önüne alındığında, bütçeden bağımsız afet zararlarının ekonomik etkilerinin giderilmesi için önce askerlik kanununa bir geçici madde eklenmiş ve geçici bedelli askerlik hizmeti uygulaması başlamıştır daha sonra kanun hükmünde kararname ile Doğal Afet Sigortaları Kurumu (DASK) kurulmuştur. Bu kurumun amacı doğal afetler 
sonrası yıkılan veya hasar gören yapıların onarılması, yeniden inşa edilebilmesi için ekonomik kaynak oluşturmaktır (Çevre ve Şehircilik Bakanlığı, 2015).

2001 yılı Türkiye'de yapıların sağlamlığı, yapı kalitesi ile ilgili bir dönüm noktası olmuş "Yapı Denetimi Hakkında Kanun Hükmünde Kararname" ile kamunun gerçekleştiremediği ve teknik açıdan yetersiz kaldığı denetleme mekanizması devlet tarafından yetkilendirilmiş özel sektöre aktarılmıştır. Bu kararnamenin getirdiği ciddi sorumluluklar özel sektörü denetleyen başka bir özel sektör firması tarafından gerçekleştirilmektedir. 2000 yılından günümüze pilot 19 ilde başlamış daha sonra ülke geneline yayılmış bu sistem yapı maliyetlerini arttırmış ancak şüphesiz yapı kalitesinde artışlara neden olmuştur. Bunun nedenlerinden biride denetleme yapan firmanın kullanım iznini takip eden 10 yıllık süre içerisinde binada meydana gelen hasarları (doğal afetler dâhil) mal sahibine tazmin etme mecburiyeti olmasıdır. Yani yapı ile ilgili sorumlulukların büyük kısmı denetleyen firmaya devredilmiştir.

1998 yılında çıkartılan yönetmelik ile başlayan teknik açıdan yaşanan gelişmeler 2007 yılında da devam etmiştir. 2007 Deprem Yönetmeliğinde 1998 yönetmeliği ile benzer olarak şu yaklaşım kabul edilmiştir "hafif şiddetteki depremler yaşandığında binaların yapısal ve yapısal olmayan sistem elemanlarının herhangi bir hasar görmemesi, orta şiddetteki depremlerde yapısal ve yapısal olmayan elemanlarda oluşabilecek hasarın onarılabilecek düzeyde olması, şiddetli depremlerde ise can kaybının yaşanmaması" şeklindedir (Anonim,1998). 2007 yılında yürürlüğe giren yönetmeliğin ülkemize getirdiği yenilik, mevcut yapıların iyileştirilmesi ve güçlendirilmesidir. Bu sayede; mevcut yapılar ile ilgili ilk kez bir karar yasalarımızda yerini bulmuştur. Yönetmelikte "Doğrusal Elastik Hesap Yöntemleri" ve "Doğrusal Olmayan Hesap Yöntemleri" ile yapıların depreme karşı davranışları bilimsel olarak belirlenmeye çalışılmıştır (Anonim, 2007). Ancak bu başka bir sorunsalın başlangıç noktası olmuştur: "Bu bilimsel yöntemler incelenmesi gereken tüm yapılara nasıl uygulanacak?"

2009 yılında yönetsel bir değişiklikle Türkiye Acil Durum Yönetimi Genel Müdürlüğü, Bayındırlık ve İskân Bakanlığı bünyesinde Afet İşleri Genel Müdürlüğü ve İçişleri Bakanlığı'na bağlı Sivil Savunma Genel Müdürlüğü, Başbakanlık bünyesinde kurulan Türkiye Afet ve Acil Durum Yönetimi Başkanlığı çatısı altında toplanmıştır. 2011 yılında ise Bayındırlık ve İskân Bakanlığı yerini Avrupa Birliği Uyum Programı kapsamında Çevre ve Şehircilik Bakanlığına bırakmıştır (Çevre ve Şehircilik Bakanlığı 2015).

Bugün Türkiye Afet ve Acil Durum Yönetimi Başkanlığı yönlendirici ve koordinatör bir kurum olarak görev yapmakta Çevre ve Şehircilik Bakanlığı ise ruhsat işlemlerinden her türlü ölçekteki fiziki planların yapılması ve uygulanmasına yönelik işlemler ve temel ilke, strateji ve standartları belirlemek ve bunların uygulanmasını sağlamakla yetkilidir.

Yaşanan tüm bu tecrübeler ve teknik gelişmeler doğrultusunda afet riski olan bölgeler ile ilgili yasal bir düzenlemenin eksikliği anlaşımış ve afet zararlarını azaltmaya yönelik ülkemizde en son olan uygulama olarak 2012 yılında "6306 Sayılı Afet Riski Altındaki Alanların Dönüştürülmesi Hakkında Kanun" yürürlüğe girmiştir. Yasa halen de yürürlüktedir.

\section{Bulgular ve Tartışma}

Çalışmanın bu aşamasına kadar bahsedilen süreçlerden de anlaşılacağı gibi ülkemizde afet zararlarını azaltmaya yönelik birçok çalışma ve kanuni düzenleme yapılmışır. Ancak zamanın koşullarının değişmesi ile yasal uygulamalarda sürekli bir değişim içinde ilerlemiştir. Mevcut düzenlemelerin finansal boyutunda ve uygulamasındaki eksiklikler nedeni ile yeni bir düzenlemeye ihtiyaç duyulmuştur.

6306 sayılı kanun beraberinde getirdiği finansal, yönetsel, teknik düzenlemeler ile komple bir yasa olarak öncesinde yapılmış düzenlemelerden farklılık göstermekte, daha çok uygulama odaklı olması ile dikkat çekmektedir. Bu yüzdendir ki yasa ideali yakalamaktan çok çözüme ve uygulamaya yönelik niteliği ile en çok eleştirilere maruz kalan yasal düzenleme olmuştur. Kanunun getirdiği yeniliklerden kısaca bahsedersek;

Yasa hem tekil bina bazında değerlendirilmeler ile hem de alan bazında değerlendirilmeler ile toplu olarak dönüşüme yönelik yöntem ve esaslara yer vermektedir. Kanun kapsamında dönüşümde temel 
alınanın yapı bazında değil yapıların topluca dönüşümünü öngören alan bazında dönüşüm olduğu ifade edilmektedir. Bu nedenle kanunda riskli olabilecek alanlar, belirlenen kriterler çerçevesinde değerlendirilmekte, uygun görülmesi halinde riskli alan ilan edilmektedir. İnceleme alanının üzerindeki yapılaşmanın ruhsatsız veya kaçak olması, mühendislik hizmeti alıp almadığı, ulaşım ağı ve altyapısının yetersiz olması riskli alan seçilmesinde gerekli koşullar olduğu belirtilmekte bunun ile ilgilide yasada "zemin yapısı veya üzerindeki yapılaşma sebebiyle can ve mal kaybına yol açma riski taşıdığına dair teknik rapor" denilmektedir ancak detaylı bir şekilde bu raporun içeriği belirtilmemektedir. Ayrıca yasada yapılarda yapılacak dışarıdan basit gözlenebilen ölçütler yardımı ile deprem riski açısından sıralama yapılması ve bu yapıların kent içindeki dağılımının tahmin edilmesinin amaçlanmaktadır (Anonim, 2012). Bu noktada da belirtilen inceleme kriterleri arasında teknik açıdan soru işaretleri bulunmaktadır.

Yasada, yapıların değerlendirilmesi sonrası riskli olarak belirlenmesinden, alan geneli tüm kararların alınması, alınan kararlar doğrultusunda tüm işlemlerin yapılması veya yaptırılması Çevre ve Şehircilik Bakanlığına devredilmiştir. Ne zaman olacağı belirlenemeyen bir afetin etkilerini en aza indirmek şüphesiz alınan hızlı kararlar ve bu kararların hayata geçirilmesi ile mümkün olacaktır. Yetkilerin tek bir kurumda toplanması bu noktada faydalı olacaktır ancak kendi uygulamalarını kendi denetleyen bir kurum beraberinde farklı sorunlara neden olacaktır.

Yasada daha önce gündeme gelmemiş birçok finansal boyut ve çözüm önerisi de yer almaktadır. Afet riski taşıyan veya taşımadığı halde uygulama bütünlüğü gerekçesi ile dönüşüm alanı içerisinde kalan taşınmaza ne şekilde müdahale edileceği (güçlendirme, yeniden inşa, kamulaştırma vs.), hak sahiplerine tanınacak haklar ve paydaşlar arasında uzlaşmanın nasıl sağlanacağı yasada ilk kez yerini bulmuştur. Bu noktada da işleyiş, yargı süreçleri ve mülkiyet hakları konusunda tartışmalar devam etmektedir.

\section{Sonuç ve Öneriler}

Bu çalışmada Tanzimat döneminde günümüze ülkemizde yapılmış afet zararlarını azaltmaya yönelik yasal çalışmalar incelenerek deprem risklerinin azaltılması sürecine sağladıkları katkılar ve gelişim süreçleri iki tarihsel dönem içerisinde incelenmiş, son olarak 6306 sayılı yasa ile gelinen nokta belirlenmiştir. İncelenen tüm bu süreçten de anlaşılacağı gibi yapılmış zarar azaltma çalışmaları ne yazık ki yaşanan talihsiz olaylar ve tecrübeler sonrası başlamış veya hız kazanmıştır. İmar afları, mevzuat ve denetim yetersizlikleri ancak afetler yaşandıktan sonra ülkemizde sorgulanır hale gelmiştir.

Bu çalışma ile tarihsel süreç içerisinde yürürlüğe girmiş yasal düzenlemelerin afet sonrası yaraları sarmakla başladığı ve zaman içerisinde daha organize ve bilimsel bir hal aldığını görmek mümkündür. Bununla birlikte ülkemizde yürürlüğe girmiş son uygulamalar ile planlama disiplini afet zararlarını azaltma çalışmalarına dâhil olmaya başlamıştır. Unutulmamalıdır ki dönüşümde sağlıklı ve ekonomik olan yapıların tek tek değerlendirilerek dönüştürülmesi değil, alanların altyapısı, üst yapısı ve donatı alanları ile birlikte değerlendirilerek bütüncül projeler çerçevesinde yeni yaşam alanlarının oluşturulmasıdır. Yürürlükte yerini bulan "alan bütünlügü̈" ve "kentsel alanların risk seviyesi" kavramları ile de sadece yapıların değil, afete maruz kalabilecek konut alanları ile birlikte sosyal ve teknik altyapı alanlarının da dönüşmesi mümkün olabilecektir.

Şüphesiz her yasal uygulama gibi bugün yürürlükte olan mevcut uygulamalarında eksikleri vardır. Bu eksikler, uygulama alanları genişledikçe, yaşanan yeni sorunlar dâhilinde kendilerinden önceki uygulamaların değişim sürecini yaşayacaklardır.

\section{Kaynaklar}

Anonim, (1962).Afet Bölgelerinde Yapılacak Yapılar Hakkında Yönetmelik, T.C. Bayındırlık Bakanlığı, Ankara

Anonim, (1968). Afet Bölgelerinde Yapılacak Yapılar Hakkında Yönetmelik, T.C. Bayındırlık Bakanlığı, Ankara 
Anonim, (1975). Afet Bölgelerinde Yapılacak Yapılar Hakkında Yönetmelik, T.C. Bayındırlık Bakanlığı, Ankara

Anonim, (1998). Afet Bölgelerinde Yapılacak Yapılar Hakkında Yönetmelik, T.C. Bayındırlık ve İskân Bakanlığı, Ankara

Anonim. (2004). JICA Türkiye' de Doğal Afetler Konulu Ülke Strateji Raporu, Ankara

Anonim, (2007). Afet Bölgelerinde Yapılacak Binalar Hakkında Yönetmelik, T.C. Bayındırlık ve İskân Bakanlığı, Ankara

Anonim, (2012). 6306 sayılı Afet Riski Altındaki Alanların Dönüştürülmesi Hakkında Kanun, 2012, Çevre ve Şehircilik Bakanlığı, Ankara

Alcantara, I. (2002). Geomorphology, Natural Hazards, Vulnerability and Preventionof Natural Disasters in Developing Countries, Geomorphology, 47, 107-124, Amsterdam

Alyamaç, K.E. ve Erdoğan A.S. (2005). Geçmişten Günümüze Afet Yönetmelikleri ve Uygulamada Karşılaşılan Tasarım Hataları, Deprem Sempozyumu, 707-715,Kocaeli

Çevre ve Şehircilik Bakanlığı. (2015). Bakanlığın Tarihçesi, https://www.csb.gov.tr/turkce/index.php?Sayfa=sayfa\&Tur=webmenu\&ld=15

Çevre ve Şehircilik Bakanlığı. (2012). Dünden Bugüne Deprem Yönetmeliği, https://www.csb.gov.tr/iller/dosyalar/dosya/il_webmenu12559.pptx

Göktürk, I. ve Yılmaz, M. (2005). Ülkemizde Afet Politikaları ve Karşılaşılan Sorunlara illişkin Bir Değerlendirme, Bayındırlık Bakanlığı, Ankara

Keleş R. (1998). Kent Bilim Terimleri Sözlüğü, İmge Kitabevi, Ankara

Taymaz , T. (Ed.), (2001). Symposia on Seismotectonics of The North-Western Anatolia - Aegean and Recent Turkish Earthquakes, 113, İstanbul

Tekdemir, A. (2011). Tanzimat Dönemi Nafia Nezareti, Trakya Üniversitesi Edebiyat Fakültesi Dergisi, 1 (1), 109-132, Edirne

Yavaş, H. (2001). Doğal Afet Yönetimi Ve Yerel Gündem 21 Çalışmaları Kapsamında İzmir'de Deprem Riski, Dokuz Eylül Üniversitesi Sosyal Bilimler Enstitüsü Dergisi, 3(3), 118-138, İzmir 